\title{
Melatonin in the management of perinatal hypoxic-ischemic encephalopathy: light at the end of the tunnel?
}

This article was published in the following Dove Press journal:

Neuropsychiatric Disease and Treatment

27 September 2016

Number of times this article has been viewed

\author{
Mohamed A Hendaus ${ }^{1,2}$ \\ Fatima A Jomha ${ }^{3}$ \\ Ahmed H Alhammadi ${ }^{1,2}$ \\ 'Department of Pediatrics, Section of \\ Academic General Pediatrics, Hamad \\ Medical Corporation, ${ }^{2}$ Department \\ of Clinical Pediatrics, Weill-Cornell \\ Medical College, Doha, Qatar; ${ }^{3}$ School \\ of Pharmacy, Lebanese International \\ University, Khiara, Lebanon
}

\begin{abstract}
Perinatal hypoxic-ischemic encephalopathy (HIE) affects one to three per 1,000 live full-term births and can lead to severe and permanent neuropsychological sequelae, such as cerebral palsy, epilepsy, mental retardation, and visual motor or visual perceptive dysfunction. Melatonin has begun to be contemplated as a good choice in order to diminish the neurological sequelae from hypoxic-ischemic brain injury. Melatonin emerges as a very interesting medication, because of its capacity to cross all physiological barriers extending to subcellular compartments and its safety and effectiveness. The purpose of this commentary is to detail the evidence on the use of melatonin as a neuroprotection agent. The pharmacologic aspects of the drug as well as its potential neuroprotective characteristics in human and animal studies are described in this study. Melatonin seems to be safe and beneficial in protecting neonatal brains from perinatal HIE. Larger randomized controlled trials in humans are required, to implement a long-awaited feasible treatment in order to avoid the dreaded sequelae of HIE.
\end{abstract}

Keywords: melatonin, hypoxia, use, encephalopathy

\section{Introduction}

Perinatal asphyxia is defined as the interference of gas exchange or blood flow to and from the fetus in the perinatal age. ${ }^{1}$ This interruption could be extended to partial asphyxia and sudden subtotal asphyxia because of a sentry experience or a combination of both. ${ }^{2}$ Hypoxic-ischemic injuries to the brain might be the outcome if the perinatal asphyxia is of an adequate intensity or extended beyond the capability of the fetus to compensate. ${ }^{3,4}$

Perinatal hypoxic-ischemic encephalopathy (HIE) affects one to three per 1,000 live full-term births. ${ }^{5,6} \mathrm{Up}$ to one-fifth of the affected newborns will perish in the postnatal period, and a further $25 \%$ will develop severe and permanent neuropsychological sequelae, such as cerebral palsy, epilepsy, mental retardation, and visual motor or visual perceptive dysfunction. ${ }^{7}$ Ensuing a hypoxic-ischemic (HI) abuse, an instantaneous phase of neuronal cell injury and enervation of energy stores occurs, followed by oxidative stress and apoptosis. ${ }^{8}$ Many crucial neuronal groups are more susceptible to HI injury in newborns than in adults, especially those related to enhanced density and function of excitatory amino acid receptors. ${ }^{9}$ The neonatal brain has higher water content, underdeveloped cortex, lower myelin, and a more conspicuous germinal matrix than the mature brain. ${ }^{10}$ The morbidity and mortality of infants are strongly affected by their ability to preserve physiologic homeostasis. ${ }^{11}$ Melatonin has begun to be contemplated as a good choice in order to diminish the neurological 
sequelae from HI brain injury. Melatonin emerges as a very interesting medication, because of its capacity to cross all physiological barriers extending to subcellular compartments and its safety and effectiveness. ${ }^{12,13}$ It effortlessly crosses the blood-brain barrier and the placenta, stretching to subcellular compartments with minimal toxicity and high effectiveness, ${ }^{12,14}$ rendering it a relatively safe treatment that could be administered to newborns. ${ }^{15}$ The purpose of this commentary is to detail the evidence on the use of melatonin as a neuroprotection agent.

\section{Search strategy and selection criteria}

A search in PubMed, Google Scholar, and Embase databases was conducted using different combinations of the following terms: melatonin, perinatal, hypoxic, encephalopathy, treatment, prevention, and strategy. Moreover, the references of the identified articles were searched for further articles. Later, the abstracts and titles were inspected, and studies that were appropriate to the topic of interest were selected. Finally, the search was restricted to manuscripts that were published in Spanish and English from inception till July 2016 (Figure 1).

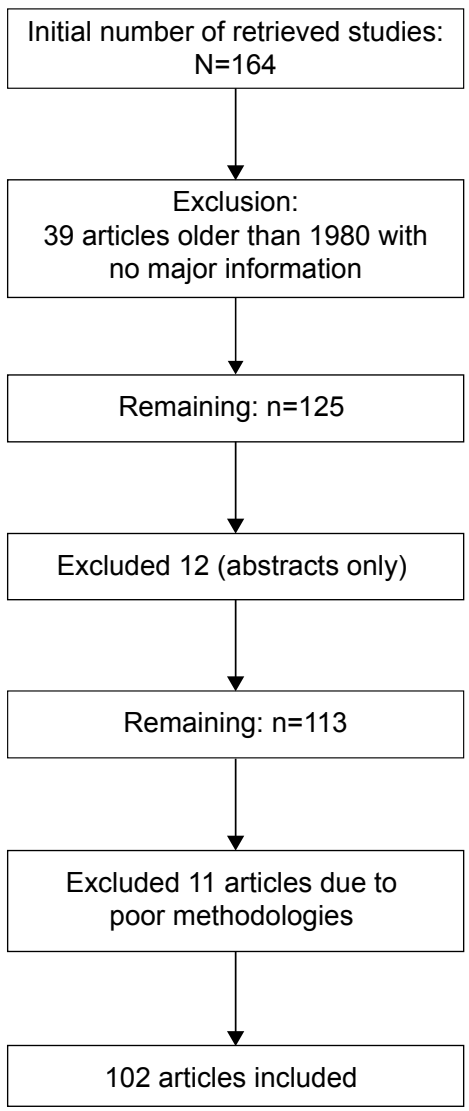

Figure I Flow diagram of selection of references.

\section{Melatonin}

Melatonin ( $\mathrm{N}$-acetyl-5-methoxytryptamine) is an endogenously produced indolamine originating from the pineal gland. ${ }^{16}$ Melatonin, a naturally appearing neuroendocrine molecule is released as a result of environmental light-dark cycles, effortlessly crosses biological membranes and performs through receptor-dependent and receptor-independent mechanisms to adjust gene expression and cell signaling. ${ }^{17,18}$ It has a short half-life. ${ }^{19,20}$ The augmentation in serum levels and excretion after oral ingestion of melatonin is rapid $(60-150 \mathrm{~min}) .{ }^{21}$ Melatonin is usually metabolized in the liver and excreted by the kidney. ${ }^{22}$

It comprises several other biological functions in various tissues and organs, ${ }^{23}$ which involve harmonizing energy metabolism, ${ }^{24}$ protecting against oxidative stress, ${ }^{25}$ delaying aging, ${ }^{26}$ and embellishing immune function. ${ }^{27}$

Autogenous melatonin is indispensable to normal neurodevelopment and preserves the developing brain from injury. ${ }^{28-30}$ Maternal melatonin levels are increased during pregnancy and melatonin effortlessly crosses the blood-brain barrier and placenta. ${ }^{31,32}$ Neonates born at term produce, to some extent, low pineal melatonin and therefore have deficiencies in diurnal variation for the first week of life. ${ }^{33}$ Moreover, another raise in serum melatonin levels occurs in very sick children as well as in patients with cerebrovascular accidents entailing an aspect of melatonin in an autogenous protective reaction. ${ }^{34,35}$

Melatonin accomplishes its strong neuroprotective result through anti-inflammatory, anti-apoptotic, and antioxidant processes through nuclear and cell membrane receptors ${ }^{28,29,36}$ and by boosting glial and neuronal development. ${ }^{37,38}$ Evolving young brain is easily exposed to free radical damage, 39,40 and the strong free radical-scavenging characteristics of melatonin and its metabolites contribute to a crucial neuroprotective process. ${ }^{25,41,42}$

Under abnormal circumstances, one of the most crucial regulators of apoptotic cell death is mitochondrial deterioration, as the severance of its membrane integrity can limit cell survival by dispensation of apoptotic proteins, impaired calcium homeostasis, and generation of reactive oxygen species. ${ }^{43}$

Studies have shown that melatonin decreased or blocked caspase (a family of protease enzymes playing essential roles in programmed cell death-1) and caspase-3 activation, ${ }^{44-46}$ interfered with release of cytochrome $c,{ }^{45,46}$ decreased Bad (B-cell lymphoma 2-associated death promoter), ${ }^{47,48}$ and $\operatorname{Bax}$ (B-cell lymphoma 2-associated $\mathrm{X}$ protein $)^{49}$ pro-apoptotic proteins, and diminished the 
number of terminal deoxynucleotidyl transferase dUTP nick end labeling (TUNEL)-positive cells. ${ }^{50-53}$ Melatonin can also produce antiexcitatory effects on neurons through the modulation of gamma-aminobutyric acid and glutamate receptors, ${ }^{54,55}$ leading to the decrease in cytosolic calcium concentrations. ${ }^{56,57}$

The approach moderated by melatonin and its main metabolites circumscribes the downregulation of some inflammation-associated molecules such as prostaglandin, ${ }^{58}$ cyclooxygenase, ${ }^{59,60} 5$-lipoxygenase, ${ }^{61}$ tumor necrosis factor- $\alpha$, cytokines, interleukin- 6 , and interleukin- $8,{ }^{62-65}$ and also the hindrance of neuronal nitric oxide (nNO). ${ }^{66,67}$ Melatonin hence diminishes vascular endothelial growth factor concentration, NO production, and, therefore, vascular permeability that results increased after hypoxic exposure. ${ }^{68}$

Other important functions of melatonin at the molecular level include maintenance of the mitochondrial integrity and the upregulation of antioxidant enzymes. ${ }^{25,42}$ Several animal studies have demonstrated that melatonin decreases oxidative injury to cerebral lipids ${ }^{69-74}$ and improves cerebral energy breakdown ${ }^{75}$ and apoptosis. ${ }^{74-78}$ Melatonin promotes protection after $\mathrm{HI}^{75-80}$ and in lipopolysaccharide-sensitized HI. ${ }^{81}$

Several actions are arbitrated through the G-proteincoupled melatonin receptors in cellular membranes. ${ }^{82}$ Other molecular actions of melatonin include its cooperation with molecules such as calmodulin in the cytosol and orphan nuclear receptors. ${ }^{83}$ Nonreceptor-mediated actions of melatonin are usually associated with its capability to detoxify reactive oxygen species. ${ }^{84}$

\section{Melatonin as a neuroprotector in animal models}

The neuroprotective outcomes of melatonin in the fetal brain have been evaluated in several animal models. Melatonin administration to both preterm and near-term fetal sheep has been demonstrated to decrease oxidative stress $^{69}$ and debilitate cell injury and death in the fetal brain, in association with a decreased inflammatory reaction. ${ }^{79}$

Following acute neonatal hemorrhagic brain injury in neonatal rats, melatonin was administered to assess germinal matrix hemorrhage. Lekic et $\mathrm{al}^{85}$ concluded that melatonin is an efficient antioxidant that can guard the infant's brain from the posthemorrhagic ramifications of mental retardation and cerebral palsy. Husson et $\mathrm{al}^{86}$ showed that melatonin, through its adenylate cyclase inhibition, showed neuroprotection of the murine periventricular white matter against neonatal excitotoxicity challenge. Mice that received melatonin through the intraperitoneal route expressed $82 \%$ reduction in size of ibotenate-induced white matter cysts. The study also concluded that melatonin can bolster secondary lesion repair of white matter lesions. Robertson et $\mathrm{al}^{75}$ studied the neuroprotective outcome of adding melatonin to therapeutic hypothermia after transient $\mathrm{HI}$ in a swine model of perinatal asphyxia using magnetic resonance spectroscopy biomarkers backed by immunohistochemistry. Amid global HI insult, 17 newborn piglets were randomized to receive either therapeutic hypothermia $\left(33.5^{\circ} \mathrm{C}\right.$ from 2 to $26 \mathrm{~h}$ after resuscitation, $\mathrm{n}=8$ ) or therapeutic hypothermia plus intravenous melatonin $(n=9)$. The dose of melatonin used was $5 \mathrm{mg} / \mathrm{kg} / \mathrm{h}$ over $6 \mathrm{~h}$ initiated at $10 \mathrm{~min}$ after resuscitation and repeated for $24 \mathrm{~h}$. The study showed that plasma levels of melatonin were 10,000 times higher in the hypothermia plus melatonin compared to the hypothermia alone group. In addition, melatonin-increased hypothermia greatly decreased the HI-induced area, as projected by the proton magnetic resonance spectroscopy lactate/ $N$-acetyl aspartate and lactate/ total creatine ratios in the deep gray matter.

Pazar et $\mathrm{al}^{87}$ investigated the neuroprotective effects of melatonin in an experimental hemolysis-induced hyperbilirubinemia in 72 newborn Sprague-Dawley rats. Phenylhydrazine hydrochloride (PHZ; $75 \mathrm{mg} / \mathrm{kg}$ ) was injected at 0 and $24 \mathrm{~h}$. The rats were administered either saline or melatonin $(10 \mathrm{mg} / \mathrm{kg}$ ) half an hour prior to the first and second PHZ injections and $24 \mathrm{~h}$ after the second PHZ injections. The control group $(n=24)$ were injected with saline, but not PHZ. The study concluded that augmented TUNEL cells in the hippocampus of saline-treated PHZ group were decreased by melatonin treatment, indicating the neuroprotective and antiapoptotic effects of melatonin on the oxidative neuronal damage of the newborn rats with hemolysis and hyperbilirubinemia.

\section{Melatonin as a neuroprotector in human clinical studies}

The neuroprotective outcomes of melatonin in the fetal brain have been assessed in several human studies. In a randomized controlled pilot study, Aly et $\mathrm{al}^{16}$ tested the clinical outcomes of melatonin and neurophysiological aftermath of neonates with HIE. The study included 45 newborns, 30 with HIE and 15 healthy controls. The dose of melatonin used was $10 \mathrm{mg} / \mathrm{kg}$ daily for a total of five doses. Serum nitric oxide (NO) and melatonin as well as plasma superoxide dismutase (SOD) were measured for the 45 newborns and at 5 days for the HIE groups $(\mathrm{N}=30)$. The study concluded that compared with healthy neonates, the HIE groups had increased melatonin, SOD, and NO. Moreover, at 5 days, the melatonin/hypothermia group 
had a higher level of melatonin $(P<0.001)$ and decrease in NO $(P<0.001)$, and SOD $(P=0.004)$. The melatonin/hypothermia group had fewer seizures on follow-up electroencephalogram and fewer white matter abnormalities on MRI. Furthermore, at 6 months, the melatonin/hypothermia group had better mortality rate without developmental or neurological abnormalities $(P<0.001)$.

Fulia et $\mathrm{al}^{88}$ investigated the implications of free radicals in the pathogenesis of neonatal asphyxia and its complications. The study that included 20 asphyxiated newborns measured malondialdehyde (a product of lipid peroxidation) and the nitrite/nitrate levels before and after the administration of melatonin within the first $6 \mathrm{~h}$ of life. One group of newborns received a total of $80 \mathrm{mg}$ of melatonin orally (eight doses of $10 \mathrm{mg}$ each separated by $2 \mathrm{~h}$ intervals). A single blood sample was gathered prior to melatonin administration, and two further blood samples (at 12 and $24 \mathrm{~h}$ ) were gathered after the oral administration of melatonin. The study showed that serum malondialdehyde and nitrite + nitrate concentrations in newborns with asphyxia prior to treatment were markedly higher than those in infants without asphyxia. In the asphyxiated group that received melatonin, there was a marked decrease in levels of malondialdehyde and nitrite/nitrate levels at both 12 and $24 \mathrm{~h}$. Thirty percent of the asphyxiated children who did not receive melatonin died within $72 \mathrm{~h}$ after birth, whereas all the asphyxiated newborns who received melatonin lived. The study concluded that the melatonin may be useful and advantageous in the management of newborn infants with asphyxia.

Carloni et $\mathrm{al}^{89}$ investigated whether administering melatonin before or after $\mathrm{HI}$ in immature rats provides significant protection and long-lasting benefit on ischemic outcomes. The authors concluded that brain injury was significantly debilitated in the melatonin-treated ischemic group. Signorini et $\mathrm{al}^{90}$ studied the production of oxidative damage mediators and the likely outcomes of melatonin administration in a model of HIE in newborn rats (7 days old). The study showed that $\mathrm{HI}$ induces an augmentation in desferrioxamine-chelatable free iron in the cerebral cortex, which can lead to cerebral oxidative stress, whereas the cerebral injury by the oxidative stress may be avoided by melatonin administration.

Maternal-fetal transfer of melatonin in pregnant women near term has been documented by measuring the concentration of melatonin in the fetal circulation after its administration. The oral administration of $3 \mathrm{mg}$ of melatonin resulted in augmentation in the serum levels with maximum values being observed $2 \mathrm{~h}$ after drug administration; the blood levels of melatonin in the umbilical vein corresponded well to those in the maternal vein. ${ }^{91}$ These results solidify the concept that melatonin is easily transferred from maternal to fetal circulation and can be an option for its therapeutic use as an antioxidant in patients with preeclampsia.

\section{Safety profiles and possible side effects of melatonin}

Human investigations have demonstrated melatonin toxicity to be very low with negligible side effects. ${ }^{16,88,92}$ Melatonin can be used in children with severe learning disorders to ameliorate sleep patterns ${ }^{93,94}$ and learning disabilities, ${ }^{93}$ in neonates with respiratory distress syndrome, ${ }^{95-97}$ and in children with attention deficit/hyperactivity disorder and chronic sleep onset insomnia. $^{98}$

Experiments on animals have shown that even high doses of melatonin (200 mg/kg/day) from gestational days 6-19 did not have any teratogenic or any negative side effect on rat newborns. ${ }^{99}$ Another study conducted by Sadowsky et $\mathrm{al}^{100}$ showed that high melatonin dose did not affect the myometrial electromyography activity in the pregnant sheep at 138-142 days gestation (term $=147$ days gestation).

However, there is a concern with regard to the inhibition effect of melatonin on the synthesis of prostaglandins, and hence on the endocrine and circulatory capacity in the fetus. ${ }^{101}$ In addition, there was a report of decreased threshold of seizure activities in four children with neurologic impairments treated with melatonin. ${ }^{102}$

\section{Conclusion}

Melatonin seems to be safe and beneficial in protecting neonatal brains from perinatal HIE. However, the number of infants included in the studies were small, and therefore, larger randomized controlled trials in humans are needed to implement a long-waited feasible treatment to avoid the dreaded sequelae of HIE.

\section{Disclosure}

The authors report no conflicts of interest in this work.

\section{References}

1. Fattuoni C, Palmas F, Noto A, Fanos V, Barberini L. Perinatal asphyxia: a review from a metabolomics perspective. Molecules. 2015;20(4): 7000-7016.

2. Fatemi A, Wilson MA, Johnston MV. Hypoxic-ischemic encephalopathy in the term infant. Clin Perinatol. 2009;36:835-858, vii.

3. Low JA. Determining the contribution of asphyxia to brain damage in the neonate. J Obstet Gynaecol Res. 2004;30:276-286.

4. Ugwumadu A. Understanding cardiotocographic patterns associated with intrapartum fetal hypoxia and neurologic injury. Best Pract Res Clin Obstet Gynaecol. 2013;27:509-536. 
5. Graham EM, Ruis KA, Hartman AL, Northington FJ, Fox HE. A systematic review of the role of intrapartum hypoxia-ischemia in the causation of neonatal encephalopathy. Am J Obstet Gynecol. 2008; 199(6):587-595.

6. Kurinczuk JJ, White-Koning M, Badawi N. Epidemiology of neonatal encephalopathy and hypoxic-ischemic encephalopathy. Early Hum Dev. 2010;86(6):329-338.

7. Vannucci RC, Perlman JM. Interventions for perinatal hypoxic-ischemic encephalopathy. Pediatrics. 1997;100(6):1004-1014.

8. Shankaran S. Neonatal encephalopathy: treatment with hypothermia. NeoReviews. 2010;11(2):e85-e92.

9. Yager JY, Thornhill JA. The effect of age on susceptibility to hypoxicischemic brain damage. Neurosci Biobehav Rev. 1997;21(2):167-174.

10. du Plessis AJ, Volpe JJ. Perinatal brain injury in the preterm and term newborn. Curr Opin Neurol. 2012;15(2):151-157.

11. Perrone S, Stazzoni G, Tataranno ML, Buonocore G. New pharmacologic and therapeutic approaches for hypoxic-ischemic encephalopathy in the newborn. J Matern Fetal Neonatal Med. 2012;25(1):83-88.

12. Gupta YK, Gupta M, Kohli K. Neuroprotective role of melatonin in oxidative stress vulnerable brain. Indian J Physiol Pharmacol. 2003; 47(4):373-386.

13. Perrone S, Tataranno LM, Stazzoni G, Ramenghi L, Buonocore G. Brain susceptibility to oxidative stress in the perinatal period. J Matern Fetal Neonatal Med. 2015;28(Suppl 1):2291-2295.

14. Menendez-Pelaez A, Reiter RJ. Distribution of melatonin in mammalian tissues: the relative importance of nuclear versus cytosolic localization. J Pineal Res. 1993;15:59-69.

15. Rees $\mathrm{S}$, Harding R, Walker $\mathrm{D}$. The biological basis of injury and neuroprotection in the fetal and neonatal brain. Int J Dev Neurosci. 2011;29: 551-563.

16. Aly H, Elmahdy H, El-Dib M, et al. Melatonin use for neuroprotection in perinatal asphyxia: a randomized controlled pilot study. J Perinatol. 2015;35(3):186-191.

17. Reiter RJ, Tan DX, Manchester LC, Pilar Terron M, Flores LJ, Koppisepi S. Medical implications of melatonin: receptor-mediated and receptor-independent actions. Adv Med Sci. 2007;52:11-28.

18. Slominski RM, Reiter RJ, Schlabritz-Loutsevitch N, Ostrom RS, Slominski AT. Melatonin membrane receptors in peripheral tissues: distribution and functions. Mol Cell Endocrinol. 2012;351:15266.

19. Shreeve N, Cagampang F, Sadek K, et al. Poor sleep in PCOS; is melatonin the culprit? Hum Reprod. 2013;28:1348-1353.

20. de Almeida E, Di Mascio P, Harumi T, et al. Measurement of melatonin in body fluids: standards, protocols and procedures. Childs Nerv Syst. 2011;27:879-891.

21. Fernando S, Rombauts L. Melatonin: shedding light on infertility? a review of the recent literature. J Ovarian Res. 2014;7:98.

22. Li C, Li G, Tan D, Li F, Ma X. A novel enzyme-dependent melatonin metabolite in humans. J Pineal Res. 2013;54:100-106.

23. Reiter R, Tan D, Fuentes-Broto L. Melatonin: a multitasking molecule. Prog Brain Res. 2010;181:127-151.

24. Leon J, Acuña-Castroviejo D, Sainz R, Mayo J, Tan D, Reiter R. Melatonin and mitochondrial function. Life Sci. 2004;75:765-790.

25. Tan DX, Manchester LC, Terron MP, Flores LJ, Tamura H, Reiter RJ. One molecule, many derivatives: a never-ending interaction of melatonin with reactive oxygen and nitrogen species? J Pineal Res. 2007;42:28-42.

26. Bubenik G, Konturek S. Melatonin and aging: prospects for human treatment. J Physiol Pharmacol. 2011;62:13-19.

27. Altun A, Ugur-Altun B. Melatonin: therapeutic and clinical utilization. Int J Clin Pract. 2007;61:835-845.

28. Cardinali DP, Pagano ES, Scacchi Bernasconi PA, Reynoso R, Scacchi P. Melatonin and mitochondrial dysfunction in the central nervous system. Horm Behav. 2013;63:322-330.

29. Pandi-Perumal SR, BaHammam AS, Brown GM, et al. Melatonin antioxidative defense: therapeutical implications for aging and neurodegenerative processes. Neurotox Res. 2013;23:267-300.

30. Sharma R, Ottenhof T, Rzeczkowska PA, Niles LP. Epigenetic targets for melatonin: induction of histone $\mathrm{H} 3$ hyperacetylation and gene expression in C17.2 neural stem cells. J Pineal Res. 2008;45:277-284.
31. Tamura H, Nakamura Y, Korkmaz A, et al. Melatonin and the ovary: physiological and pathophysiological implications. Fertil Steril. 2009;92:328-343.

32. Tamura H, Nakamura Y, Terron MP, et al. Melatonin and pregnancy in the human. Reprod Toxicol. 2008;25:291-303.

33. Ardura J, Gutierrez R, Andres J, Agapito T. Emergence and evolution of the circadian rhythm of melatonin in children. Horm Res. 2003;59: $66-72$.

34. Seifman M, Adamides A, Nguyen P, et al. Endogenous melatonin increases in cerebrospinal fluid of patients after severe traumatic brain injury and correlates with oxidative stress and metabolic disarray. J Cereb Blood Flow Metab. 2008;28:684-696.

35. Marseglia L, Aversa S, Barberi I, et al. High endogenous melatonin levels in critically ill children: a pilot study. J Pediatr. 2013;162:357-360.

36. Jou MJ, Peng TI, Yu PZ, et al. Melatonin protects against common deletion of mitochondrial DNA-augmented mitochondrial oxidative stress and apoptosis. J Pineal Res. 2007;43:389-403.

37. Fu J, Zhao SD, Liu HJ, et al. Melatonin promotes proliferation and differentiation of neural stem cells subjected to hypoxia in vitro. J Pineal Res. 2011;51:104-112.

38. Villapol S, Fau S, Renolleau S, Biran V, Charriaut-Marlangue C, Baud O. Melatonin promotes myelination by decreasing white matter inflammation after neonatal stroke. Pediatr Res. 2011;69:51-55.

39. Pearce W. Hypoxic regulation of the fetal cerebral circulation. $J$ Appl Physiol. 2006;100:731-738.

40. Vento M, Escobar J, Cernada M, Escrig R, Aguar M. The use and misuse of oxygen during the neonatal period. Clin Perinatol. 2012;39: $165-176$.

41. Galano A, Tan DX, Reiter RJ. On the free radical scavenging activities of melatonin's metabolites, AFMK and AMK. J Pineal Res. 2013;54: $245-257$.

42. Hardeland R, Tan DX, Reiter RJ. Kynuramines, metabolites of melatonin and other indoles: the resurrection of an almost forgotten class of biogenic amines. J Pineal Res. 2009;47:109-126.

43. Elmore S. Apoptosis: a review of programmed cell death. Toxicol Pathol. 2007;35(4):495-516.

44. Kilic E, Kilic U, Reiter RJ, Bassetti CL, Hermann DM. Tissueplasminogen activator-induced ischemic brain injury is reversed by melatonin: role of inos and akt. J Pineal Res. 2005;39:151-155.

45. Andrabi SA, Sayeed I, Siemen D, Wolf G, Horn TF. Direct inhibition of the mitochondrial permeability transition pore: a possible mechanism responsible for anti-apoptotic effects of melatonin. FASEB J. 2004; 18: 869-871.

46. Wang X, Figueroa BE, Stavrovskaya IG, et al. Methazolamide and melatonin inhibit mitochondrial cytochrome $\mathrm{C}$ release and are neuroprotective in experimental models of ischemic injury. Stroke. 2009; 40:1877-1885.

47. Ebadi M, Sharma SK, Ghafourifar P, Brown-Borg H, El Refaey H. Peroxynitrite in the pathogenesis of Parkinson's disease and the neuroprotective role of metallothioneins. Methods Enzymol. 2005;396:276-298.

48. Koh PO. Melatonin attenuates the focal cerebral ischemic injury by inhibiting the dissociation of pBad from 14-3-3. J Pineal Res. 2008;44:101-106.

49. Jang $\mathrm{MH}$, Jung $\mathrm{SB}$, Lee $\mathrm{MH}$, et al. Melatonin attenuates amyloid beta25-35-induced apoptosis in mouse microglial bv2 cells. Neurosci Lett. 2005;380:26-31.

50. Feng Z, Cheng Y, Zhang JT. Long-term effects of melatonin or 17 beta-estradiol on improving spatial memory performance in cognitively impaired, ovariectomized adult rats. J Pineal Res. 2004;37:198-206.

51. Deng YQ, Xu GG, Duan P, Zhang Q, Wang JZ. Effects of melatonin on wortmannin-induced TAU hyperphosphorylation. Acta Pharmacol Sin. 2005;26:519-526.

52. Sun FY, Lin X, Mao LZ, et al. Neuroprotection by melatonin against ischemic neuronal injury associated with modulation of DNA damage and repair in the rat following a transient cerebral ischemia. $J$ Pineal Res. 2002;33:48-56.

53. Chung SY, Han SH. Melatonin attenuates kainic acid-induced hippocampal neurodegeneration and oxidative stress through microglial inhibition. J Pineal Res. 2003;34:95-102. 
54. Molina-Carballo A, Munoz-Hoyos A, Sanchez-Forte M, UberosFernandez J, Moreno-Madrid F, Acuna-Castroviejo D. Melatonin increases following convulsive seizures may be related to its anticonvulsant properties at physiological concentrations. Neuropediatrics. 2007; $38: 122-125$

55. Rosenstein RE, Cardinali DP. Central gabaergic mechanisms as targets for melatonin activity in brain. Neurochem Int. 1990;17:373-379.

56. Prada C, Udin SB. Melatonin decreases calcium levels in retinotectal axons of xenopus laevis by indirect activation of group iii metabotropic glutamate receptors. Brain Res. 2005;1053:67-76.

57. Prada C, Udin SB, Wiechmann AF, Zhdanova IV. Stimulation of melatonin receptors decreases calcium levels in xenopus tectal cells by activating gaba(c) receptors. $J$ Neurophysiol. 2005;94:968-978.

58. Carrillo-Vico A, Garcia-Maurino S, Calvo JR, Guerrero JM. Melatonin counteracts the inhibitory effect of PGE2 on IL-2 production in human lymphocytes via its mt1 membrane receptor. FASEB J. 2003;17: $755-757$.

59. Deng WG, Tang ST, Tseng HP, Wu KK. Melatonin suppresses macrophage cyclooxygenase- 2 and inducible nitric oxide synthase expression by inhibiting p52 acetylation and binding. Blood. 2006;108: $518-524$.

60. Mayo JC, Sainz RM, Tan DX, et al. Anti-inflammatory actions of melatonin and its metabolites, $N 1$-acetyl- $N 2$-formyl-5-methoxykynuramine (AFMK) and N1-acetyl-5-methoxykynuramine (AMK), in macrophages. J Neuroimmunol. 2005;165:139-149.

61. Steinhilber D, Brungs M, Werz O, et al. The nuclear receptor for melatonin represses 5-lipoxygenase gene expression in human B lymphocytes. J Biol Chem. 1995;270:7037-7040.

62. Baykal A, Iskit AB, Hamaloglu E, Guc MO, Hascelik G, Sayek I. Melatonin modulates mesenteric blood flow and TNF $\alpha$ concentrations after lipopolysaccharide challenge. Eur J Surg. 2000;166:722-727.

63. Wang H, Wei W, Shen YX, et al. Protective effect of melatonin against liver injury in mice induced by bacillus calmette-guerin plus lipopolysaccharide. World J Gastroenterol. 2004;10:2690-2696.

64. Perianayagam MC, Oxenkrug GF, Jaber BL. Immune-modulating effects of melatonin, $\mathrm{N}$-acetylserotonin, and $\mathrm{N}$-acetyldopamine. Ann N Y Acad Sci. 2005;1053:386-393.

65. Carrillo-Vico A, Lardone PJ, Fernandez-Santos JM, et al. Human lymphocyte-synthesized melatonin is involved in the regulation of the interleukin-2/interleukin-2 receptor system. J Clin Endocrinol Metab. 2005;90:992-1000.

66. Jimenez-Ortega V, Cano P, Cardinali DP, Esquifino AI. 24-Hour variation in gene expression of redox pathway enzymes in rat hypothalamus: effect of melatonin treatment. Redox Rep. 2009;14:132-138.

67. Acuna-Castroviejo D, Escames G, Lopez LC, Hitos AB, Leon J. Melatonin and nitric oxide: two required antagonists for mitochondrial homeostasis. Endocrine. 2005;27:159-168.

68. Kaur C, Sivakumar V, Lu J, Tang FR, Ling EA. Melatonin attenuates hypoxia-induced ultrastructural changes and increased vascular permeability in the developing hippocampus. Brain Pathol. 2008;18:533-547.

69. Miller SL, Yan EB, Castillo-Meléndez M, Jenkin G, Walker DW. Melatonin provides neuroprotection in the late-gestation fetal sheep brain in response to umbilical cord occlusion. Dev Neurosci. 2005; 27(2-4):200-210.

70. Wakatsuki A, Okatani Y, Shinohara K, Ikenoue N, Fukaya T. Melatonin protects against ischemia/reperfusion-induced oxidative damage to mitochondria in fetal rat brain. J Pineal Res. 2001;31:167-172.

71. Wakatsuki A, Okatani Y, Shinohara K, Ikenoue N, Kaneda C, Fukaya T. Melatonin protects fetal rat brain against oxidative mitochondrial damage. J Pineal Res. 2001;30:22-28.

72. Watanabe K, Wakatsuki A, Shinohara K, Ikenoue N, Yokota K, Fukaya $\mathrm{T}$. Maternally administered melatonin protects against ischemia and reperfusion-induced oxidative mitochondrial damage in premature fetal rat brain. J Pineal Res. 2004;37:276-280.

73. Watanabe K, Hamada F, Wakatsuki A, et al. Prophylactic administration of melatonin to the mother throughout pregnancy can protect against oxidative cerebral damage in neonatal rats. J Matern Fetal Neonatal Med. 2012;25:1254-1259.
74. Yawno T, Castillo-Melendez M, Jenkin G, Wallace EM, Walker DW, Miller SL. Mechanisms of melatonin-induced protection in the brain of late gestation fetal sheep in response to hypoxia. Dev Neurosci. 2012; 34:543-551

75. Robertson NJ, Faulkner S, Fleiss B, et al. Melatonin augments hypothermic neuroprotection in a perinatal asphyxia model. Brain. 2013; 136(Pt 1):90-105.

76. Cetinkaya M, Alkan T, Ozyener F, Kafa IM, Kurt MA, Koksal N. Possible neuroprotective effects of magnesium sulfate and melatonin as both pre- and post-treatment in a neonatal hypoxic-ischemic rat model. Neonatology. 2011;99:302-310.

77. Hutton LC, Abbass M, Dickinson H, Ireland Z, Walker DW. Neuroprotective properties of melatonin in a model of birth asphyxia in the spiny mouse (Acomys cahirinus). Dev Neurosci. 2009;31:437-451.

78. Kaur C, Sivakumar V, Ling EA. Melatonin protects periventricular white matter from damage due to hypoxia. J Pineal Res. 2010;48:185-193.

79. Welin AK, Svedin P, Lapatto R, et al. Melatonin reduces inflammation and cell death in white matter in the mid-gestation fetal sheep following umbilical cord occlusion. Pediatr Res. 2007;61(2):153-158.

80. Balduini $\mathrm{W}$, Carloni S, Perrone S, et al. The use of melatonin in hypoxicischemic brain damage: an experimental study. J Matern Fetal Neonatal Med. 2012;25(Suppl 1):119-124.

81. Wang X, Svedin P, Nie C, et al. N-acetylcysteine reduces lipopolysaccharide-sensitized hypoxic-ischemic brain injury. Ann Neurol. 2007; 61:263-271.

82. Luchetti F, Canonico B, Betti M, et al. Melatonin signaling and cell protection function. FASEB J. 2010;24:3603-3624.

83. Benítez-King G, Antón-Tay F. Calmodulin mediates melatonin cytoskeletal effects. Experientia. 1993;49(8):635-641.

84. Tan D, Reiter R, Manchester L, et al. Chemical and physical properties and potential mechanisms: melatonin as a broad spectrum antioxidant and free radical scavenger. Curr Top Med Chem. 2002;2:181-197.

85. Lekic T, Manaenko A, Rolland W, et al. Neuroprotection by melatonin after germinal matrix hemorrhage in neonatal rats. Acta Neurochir Suppl. 2011;111:201-206.

86. Husson I, Mespls B, Bac P, Vamecq J, Evrard P, Gressens P. Melatoninergic neuroprotection of the murine periventricular white matter against neonatal excitotoxic challenge. Ann Neurol. 2002;51(1):82-92.

87. Pazar A, Kolgazi M, Memisoglu A, et al. The neuroprotective and antiapoptotic effects of melatonin on hemolytic hyperbilirubinemia-induced oxidative brain damage. J Pineal Res. 2016;60(1):74-83.

88. Fulia F, Gitto E, Cuzzocrea S, et al. Increased levels of malondialdehyde and nitrite/nitrate in the blood of asphyxiated newborns: reduction by melatonin. J Pineal Res. 2001;31(4):343-349.

89. Carloni S, Perrone S, Buonocore G, Longini M, Proietti F, Balduini W. Melatonin protects from the long-term consequences of a neonatal hypoxicischemic brain injury in rats. J Pineal Res. 2008;44(2):157-164.

90. Signorini C, Ciccoli L, Leoncini S, et al. Free iron, total F-isoprostanes and total F-neuroprostanes in a model of neonatal hypoxic-ischemic encephalopathy: neuroprotective effect of melatonin. J Pineal Res. 2009; 46(2):148-154.

91. Okatani Y, Okamoto K, Hayashi K, Wakatsuki A, Tamura S, Sagara Y. Maternal-fetal transfer of melatonin in pregnant women near term. J Pineal Res.1998;25(3):129-134.

92. Seabra ML, Bignotto M, Pinto LR Jr, Tufik S. Randomized, doubleblind clinical trial, controlled with placebo, of the toxicology of chronic melatonin treatment. J Pineal Res. 2000;29(4):193-200.

93. Gordon N. The therapeutics of melatonin: a pediatric perspective. Brain Dev. 2000;22(4):213-217.

94. Buscemi N, Vandermeer B, Hooton N, et al. Efficacy and safety of exogenous melatonin for secondary sleep disorders and sleep disorders accompanying sleep restriction: meta-analysis. BMJ. 2006;332:385-393.

95. Gitto E, Reiter RJ, Cordaro SP, et al. Oxidative and inflammatory parameters in respiratory distress syndrome of preterm newborns: beneficial effects of melatonin. Am J Perinatol. 2004;21:209-216.

96. Gitto E, Reiter RJ, Amodio A, et al. Early indicators of chronic lung disease in preterm infants with respiratory distress syndrome and their inhibition by melatonin. J Pineal Res. 2004;36(4):250-255. 
97. Gitto E, Karbownik M, Reiter RJ, et al. Effects of melatonin treatment in septic newborns. Pediatr Res. 2001;50:756-760.

98. Hoebert M, van der Heijden KB, van Geijlswijk IM, Smits MG. Longterm follow up of melatonin treatment in children with ADHD and chronic sleep onset insomnia. J Pineal Res. 2009;47(1):1-7.

99. Jahnke G, Marr M, Myers C, Wilson R, Travlos G, Price C. Maternal and developmental toxicity evaluation of melatonin administered orally to pregnant Sprague-Dawley rats. Toxicol Sci. 1999;50(2): 271-279.
100. Sadowsky DW, Yellon S, Mitchell MD, Nathanielsz PW. Lack of effect of melatonin on myometrial electromyographic activity in the pregnant sheep at $138-142$ days gestation (term $=147$ days gestation). Endocrinology. 1991;128(4):1812-1818.

101. Leach C, Thorburn GD. A comparison of the inhibitory effects of melatonin and indomethacin on platelet aggregation and thromboxane release. Prostaglandins. 1980;20(1):51-56.

102. Sheldon SH. Pro-convulsant effects of oral melatonin in neurologically disabled children. Lancet. 1998;351(9111):1254.

\section{Publish your work in this journal}

Neuropsychiatric Disease and Treatment is an international, peerreviewed journal of clinical therapeutics and pharmacology focusing on concise rapid reporting of clinical or pre-clinical studies on a range of neuropsychiatric and neurological disorders. This journal is indexed on PubMed Central, the 'PsycINFO' database and CAS, and is the official journal of The International Neuropsychiatric Association (INA). The manuscript management system is completely online and includes a very quick and fair peer-review system, which is all easy to use. Visit http://www.dovepress.com/testimonials.php to read real quotes from published authors.

Submit your manuscript here: http://www.dovepress.com/neuropsychiatric-disease-and-treatment-journal 